occupations specially authorized for the scheme. The training will be provided at certain Government training centres administered by the Ministry of Labour, at special centres with experience in training disabled persons for industry, at technical colleges and similar institutions and at works. A maximum period of twenty-six weeks training will probably be sufficient. Throughout the training, in addition to proper medical supervision, weekly allowances varying from $42 s$. to $17 s$. for men and boys and $33 s$. to 15s. for women and girls will be paid, and each trainee will also receive a dinner meal or $5 s$. per week in lieu, daily travelling expenses, when necessary, and dependants' allowances. These allowances will be independent of any pension or other payment the trainee may receive in respect of his or her disability.

\section{Evaluation of Individual Adjustment}

"AN Evaluation of Adjustment based upon the Concept of Security" by Mary D. Salter has been published in the University of Toronto Studies (Child Development Series No. 18. Toronto: University of Toronto Press ; London : Oxford University Press, 1940. 3s. net) as the first part of a larger study designed to provide an evaluation of important aspects of an individual's adjustment by means of a series of scales based upon the common concept of security. The technique used in this investigation utilizes the principle of internal consistency to construct an extra-familial and a familial scale of security designed to throw light on relations outside and inside the family, respectively. The results indicate that social insecurity appears most frequently with those who are dependently secure in the family and with those who are insecure and independent in the family. Tolerance is much more frequent with independence than it is with dependence, both for the socially insecure and the socially secure groups. Those who are socially secure and dependent tend to intolerance and familial insecurity.

Familial security in the early stages is of a dependent type and forms a basis from which the individual can work out gradually, forming new skills and interests in other fields. In its absence the individual is handicapped by the lack of a secure base from which to work, and at the college age such insecurity is at least partly due to friction on the issue of emancipation. Independence of the family is true independent security if the individual has formed requisite skills and dependencies outside the family without being involved in conflict with the family. Continued dependence on the family may make for inadequate adjustment if it seriously interferes with the development of skills in other fields. Extra-familial security is based partly upon social skills and partly upon dependencies on friends, both apparently being necessary and interrelated. Insecurity is due to a lack of skills or of friends or of both. Intolerance is a common form of compensation which may contribute to social security during the acquisition of skills, and is most effective if the individual has dependent security also or at least a fairly satisfactory basis of skills already formed. Lacking both these, compensation either becomes ineffective resulting in insecurity, or must be exaggerated to avoid insecurity, leading to the unusual forms of behaviour which characterize serious maladjustment.

\section{University Staffs in the British Empire}

ThE "Yearbook of the Universities of the Empire" is an invaluable reference book, the last issue of which is dated 1940. In view of the numerous changes, probably mostly due directly to the War, which have occurred during the past eighteen months or so in the staffs of universities, this issue quickly lost much of its value. When, however, the Universities Bureau had to consider the preparation of the issue for 1941, it was found that, on account of the destruction of the Bureau's premises, the delays in obtaining information from overseas and the shortage of paper, it was possible to prepare only a Supplement to the existing volume (Supplement to the Yearbook of the Universities of the Empire, 1940. Published for the Universities Bureau of the British Empire. Pp. xxxi+255. London: G. Bell and Sons, Ltd., 1941. 3s. 6d. net). In this book, which is of the same format as the well-known Yearbook, the officers are given for each university followed by a list of changes of staff. The list is carefully set out to facilitate easy reference, and there is an index of names at the end of the volume. The Yearbook for 1940, with the Supplement, provide as up-to-date a record of university staffs in the British Empire as is feasible in these times. The Bureau is to be congratulated on its enterprise.

\section{Tar Oil Washes}

THE introduction of tar oil washes in Great Britain about 1921 resulted in the greatest advance in the control of fruit pests that has been made during the present century. With extension in their use came the demand for their standardization, as differences in source and process of manufacture had led to un certainty in their performance. After a study of the insecticidal properties of the various components of the washes and their behaviour under different conditions had been made both at the research stations and the research departments of insecticide manufacturers, a small joint committee of representatives of the Association of British Insecticide Manufacturers and the Ministry of Agriculture was set up to consider the available information, and, if possible, to prepare specifications. After still further investigation, specifications and methods of analysis for both the miscible oil (black fluid) type and the stock emulsion (mayonnaise) type were successfully drawn up, which have been accepted by the Association and the Ministry, with the concurrence of the Government Chemist. The full data are available in Bulletin 122 of the Ministry of Agriculture (H.M. Stationery Office, 6d.). Members of the Association and most of the manufacturers of tar oil washes have agreed that their products shall conform to these standards, and purchasers are strongly advised to take advantage of this by requiring that any washes they obtain shall comply with the specifications. 